\title{
EFEITO DE FERTILIZANTES NITROGENADOS NA PRODUTIVIDADE DE MELÃO
}

\author{
JOSÉ MONTEIRO SOARES ${ }^{2}$, LUIZA TEIXEIRA DE LIMA BRITO³, NIVALDO DUARTE COSTA², \\ JOSÉ LINS MACIEL ${ }^{4}$ e CLEMENTINO MARCOS BATISTA DE FARIA ${ }^{2}$
}

RESUMO - Em Petrolina, PE, foi realizado um estudo com a cultura do melão (Cucumis melo L.), Valenciano Amarelo, num Latossolo, para avaliar o efeito de fontes de fertilizantes nitrogenados e de suas combinações. O delineamento experimental foi em blocos casualizados com arranjo em faixa, com quatro repetições e nove tratamentos englobando a testemunha e os fertilizantes nitrogenados na dose de $80 \mathrm{~kg} / \mathrm{ha}$ de $\mathrm{N}$, aplicados no solo e, ou, via água de irrigação, por um período de 42 dias após a germinação. Esses tratamentos foram: Uréia e Sulfato de Amônio isolados; Uréia (15 dias) + Nitrato de Potássio (16-42 dias); Uréia (15 dias) + Sulfato de Amônio (16-42 dias); Uréia (30 dias) + Nitrato de Potássio (31-42 dias); Uréia (15 dias) + Sulfato de Amônio (16-30 dias) + Nitrato de Potássio (31-42 dias). A uréia aplicada via fertirrigação até 42 dias proporcionou maior rendimento $(31,14 \mathrm{t} / \mathrm{ha})$, embora não estatisticamente diferente dos demais tratamentos. A testemunha e o sulfato de amônio mostraram-se menos produtivos, com rendimentos de 25,06 e 24,65 t/ha, respectivamente. O peso médio do fruto variou de 1,63 a 1,84 kg/fruto, e o teor de sólidos solúveis totais, de 12,1 a $13,1{ }^{\circ}$ Brix; não se verificaram diferenças estatísticas.

Termos para indexação: nitrogênio, fertirrigação, nutrição de plantas, Cucumis melo, irrigação.

\section{NITROGEN FERTILIZER EFFECTS ON THE MELON CROP YIELD}

ABSTRACT - A study was carried at Petrolina-PE, Brazil, with the melon crop (Cucumis melo L.), cv. Valenciano Amarelo, in a Red-Yellow Latosol with the objective of evaluating the effect of nitrogen fertilizers sources and their combinations, applied through the conventional way and through water irrigation during the crop cycle. The experimental design was a split block with four replications and nine treatments: 1. control (without N); 2. urea; 3. ammonium sulphate, both applied conventionally; 4. urea applied up to 42 days after germination; 5. ammonium sulphate applied up to 42 days after germination; 6 . urea applied up to 15 days and potassium nitrate from 16 to 42 days after germination; 7. urea applied up to 15 days and ammonium sulphate from 16 to 42 days; 8 . urea applied up to 30 days and potassium nitrate from 31 to 42 days, and 9 . urea applied up to 15 days, ammonium sulphate from 16 to 30 days and potassium nitrate from 31 to 42 days, at the level of $80 \mathrm{~kg} / \mathrm{ha}$ of N. The fertilizers used during the crop cycle (treatments 4 to 9 ) were applied through irrigation water. It was found that urea applied through fertirrigation up to 42 days provided higher yield ( 31.14 ton/ha), not differing, however, from the other treatments, with the exception of the control and ammonium sulphate, which gave the lowest yields (25.06 and 24.65 ton/ha, respectively). It was found a variation in fruit mean weight from 1.63 to $1.84 \mathrm{~kg} /$ fruit. There was no significant difference in total soluble solid content ( ${ }^{\circ}$ Brix ) among the treatments.

Index terms: nitrogen, fertirrigation, nutrition, Cucumis melo, irrigation.

${ }^{1}$ Aceito para publicação em 15 de outubro de 1998. Contribuição do convênio Embrapa/Petrobrás.

${ }^{2}$ Eng. Agr., M.Sc., Embrapa-Centro de Pesquisa Agropecuária do Trópico Semi-Árido (CPATSA), Caixa Postal 23, CEP 56300-000 Petrolina, PE. E-mail: monteiro@cpatsa.embrapa.br

${ }^{3}$ Eng. Agríc., M.Sc., Embrapa-CPATSA.

${ }^{4}$ Eng. Agríc., EBDA, Praça Imaculada Conceição, 28. CEP 48900-000 Juazeiro, BA.

\section{INTRODUÇÃO}

A região Nordeste é a maior produtora de frutos de melão no Brasil, principalmente nos Estados do Rio Grande do Norte, Pernambuco, Ceará, Bahia e Paraíba. Esta hortaliça tem grande participação na pauta de exportação. Apenas no biênio 95/96 foram exportadas 84 mil toneladas de frutos frescos de 
melão, perfazendo uma receita de, aproximadamente, 43 milhões de dólares. Deste total, o pólo Petrolina, PE/Juazeiro, BA contribuiu com 4,3 mil toneladas de frutos, com uma cotação de $1,8 \mathrm{mi}$ lhões de dólares (Brasil, 1996).

Diante da importância desta cultura para a região, houve uma grande demanda de informações visando definir um sistema produtivo que apresentasse redução de custos, aumentasse a produtividade, e atendesse às exigências dos mercados consumidores quanto à qualidade dos frutos.

A fertirrigação é uma prática usada em larga escala e tem grande aceitação pelos produtores, dada a economia de mão-de-obra e de energia, eficiência de uso e economia de fertilizantes, flexibilidade de aplicação parcelada de fertilizantes, e melhor utilização dos equipamentos de irrigação (Vitti et al., 1995). No entanto, não existem informações suficientes sobre o manejo dos fertilizantes via água de irrigação para a maioria das culturas irrigadas.

A Embrapa-Centro de Pesquisa Agropecuária do Trópico Semi-Árido (CPATSA) iniciou pesquisas em fertirrigação a partir de meados da década de 80 . Os resultados destes estudos mostram que para a cultura do melão deve-se aplicar $80 \mathrm{~kg} / \mathrm{ha}$ de $\mathrm{N}$ diariamente, no período de 3 a 42 dias após a germinação (Pinto et al., 1993, 1994 e 1996). Em experimentos com outras culturas como o tomateiro rasteiro, conduzidos no Submédio São Francisco, Pinto et al. (1997) observaram que a aplicação de N via água de irrigação foi mais eficiente do que quando aplicado no solo. A dose adequada de $\mathrm{N}$ para a cultura do melão irrigado, nessa região, tem sido em torno de $80 \mathrm{~kg} / \mathrm{ha}$, aplicado no solo (Faria et al., 1994).

No Rio Grande do Norte, os agricultores usam várias fontes de $\mathrm{N}$ em períodos diferentes do meloeiro fertirrigado, por acreditarem ser mais eficiente do que uma única fonte. Em outras regiões, algumas pesquisas têm demonstrado que o amônio como única fonte de $\mathrm{N}$ para nutrição do melão foi menos eficiente que o nitrato ou da combinação de ambos (Hanada, 1980; Elamin \& Wilcox, 1986). Raij et al. (1996) recomendam que as fontes de nutrientes para o melão devem conter parte do $\mathrm{N}$ na forma nítrica, como o nitrocálcio, nitrato de amônio e nitrato de potássio.
Este trabalho avaliou o efeito de diferentes fertilizantes nitrogenados, e de suas combinações, aplicados no solo e via água de irrigação, na cultura do melão.

\section{MATERIAL E MÉTODOS}

Os ensaios foram conduzidos no Campo Experimental de Bebedouro, da Embrapa-CPATSA, localizado em Petrolina, PE, com a cultura do melão, cultivar Valenciano Amarelo, no período de outubro/95 a janeiro/96.

Utilizou-se um Latossolo Vermelho-Amarelo, textura arenosa, com profundidade média de $1,5 \mathrm{~m}$, baixa capacidade de troca de cátions e baixo teor de matéria orgânica (Pereira \& Souza, 1967), com baixa capacidade de retenção de umidade (Choudhury \& Millar, 1981). Como características químicas da camada arável, observou-se: $\mathrm{pH}\left(\mathrm{H}_{2} \mathrm{O}\right)=6,9 ; \mathrm{P}=5,8 \mathrm{mg} / \mathrm{dm}^{3} ; \mathrm{K}, \mathrm{Ca}, \mathrm{Mg}$ e $\mathrm{Al}=0,16$, $1,8,0,6$ e $0,05 \mathrm{cmol}_{\mathrm{c}} / \mathrm{dm}^{3}$, respectivamente.

O delineamento experimental foi em blocos casualizados, com arranjo em faixa, com quatro repetições. Os tratamentos consistiram de: 1) testemunha (sem nitrogênio); 2) uréia, aplicada no solo; 3) sulfato de amônio, aplicado no solo; 4) uréia, aplicada até 42 dias após a germinação; 5) sulfato de amônio, até 42 dias após a germinação; 6) uréia, até 15 dias, e nitrato de potássio, de 16 a 42 dias após a germinação; 7) uréia, até 15 dias, e sulfato de amônio, de 16 a 42 dias após a germinação; 8) uréia, até 30 dias, e nitrato de potássio, de 31 a 42 dias após a germinação; e 9) uréia, até 15 dias, sulfato de amônio de 16 a 30 dias, e nitrato de potássio, de 31 a 42 dias após a germinação. Todos os tratamentos receberam a dose de $80 \mathrm{~kg} /$ ha de $\mathrm{N}$. Nos tratamentos 4 a 9 , o nitrogênio foi aplicado diariamente, via água de irrigação, parcelado em 40 partes iguais.

O espaçamento utilizado foi de $1,80 \mathrm{~m}$ entre linhas por $0,50 \mathrm{~m}$ entre plantas, com uma planta por cova. Todos os tratamentos receberam uma adubação uniforme com $120 \mathrm{~kg} / \mathrm{ha} \mathrm{de} \mathrm{P}_{2} \mathrm{O}_{5}$ e $90 \mathrm{~kg} / \mathrm{ha} \mathrm{de} \mathrm{K}_{2} \mathrm{O}$, tendo como fontes o superfosfato simples, que foi aplicado no plantio, e o cloreto de potássio, aplicado em cobertura diariamente, via fertirrigação no período de 3 a 42 dias após a germinação.

No período que antecedeu à cultura do melão, foi cultivada na área a Crotalaria spectabilis, visando reduzir a incidência de nematóides do gênero Meloidogyne; ela foi incorporada ao solo na fase de floração, apresentando uma média de 37 t/ha de matéria verde (Choudhury et al., 1991).

Adotou-se o sistema de irrigação por gotejamento em linha, com gotejadores no espaçamento de $1,0 \mathrm{~m}$ e vazão de $4 \mathrm{~L} / \mathrm{h}$ e pressão de $0,10 \mathrm{Mpa}$. As irrigações foram 
feitas diariamente, com base na evaporação da água (Ev), medida no tanque classe $\mathrm{A}$, no coeficiente de cultura $(\mathrm{Kc})$ e na eficiência de irrigação (Ei). Procurou-se minimizar as perdas de água por percolação abaixo da profundidade efetiva das raízes, por meio do monitoramento da umidade do solo com o uso de tensiômetros de mercúrio, instalados a 0,15 e $0,30 \mathrm{~m}$ de profundidade.

Foram realizadas duas colheitas: uma, aos 62, e a outra, 70 dias após o plantio. Além de produtividade, foram avaliados o peso médio dos frutos e o teor de sólidos solúveis ( ${ }^{\circ}$ Brix), e efetuada a classificação dos frutos por tipo, de acordo com os padrões exigidos pelos mercados interno e externo.

\section{RESULTADOS E DISCUSSÃO}

A produtividade, o peso médio do fruto e o teor de sólidos solúveis totais ( ${ }^{\circ}$ Brix), em função dos tratamentos, estão apresentados na Tabela 1. Observou-se que a uréia, aplicada via água de irrigação até 42 dias após a germinação, proporcionou uma produtividade significativamente superior às da testemunha, sulfato de amônio aplicado no solo e uréia + nitrato de potássio (16 - 42 dias). Contudo, não diferiu dos demais tratamentos.
Quanto ao peso médio de fruto, observa-se que a testemunha (sem nitrogênio), a uréia e o sulfato de amônio aplicados de forma convencional diferiram do tratamento com a uréia aplicada via água de irrigação até 42 dias após a germinação, que apresentou maior peso médio. Segundo Gorgatti Neto et al. (1994), há mercado para frutos com até $2,0 \mathrm{~kg}$. Esta é uma característica determinante para a comercialização do produto, pois, atualmente, a maior demanda de frutos de melão pelo mercado externo é pelos tipos 8 a 10, e pelo mercado interno é pelos tipos 6 a 8 . Assim, analisando a Tabela 1, verifica-se que, em média, $80 \%$ da produtividade acumulada de frutos, concentra-se entre os tipos 6 a 8 , que atende satisfatoriamente aos mercados interno e externo.

Não se constataram diferenças significativas quanto ao teor de sólidos solúveis, cujos valores oscilaram entre 12,1 e $13,1^{\circ}$ Brix, o que corrobora os resultados encontrados por Suarez \& Ramirez (1985) e Yamaguchi et al. (1977), que relatam que a exigência do teor de sólidos solúveis totais para o mercado de exportação deve ser, no mínimo, de $9^{\circ}$ Brix. No entanto, Gorgatti Neto et al. (1994) salientam que frutos com Brix inferior a 9 não são

TABELA 1. Produtividade (PR), peso médio (PM), teor de sólidos solúveis (TSS) e tipos de melão, em função dos fertilizantes nitrogenados uréia (UR), sulfato de amônio (SA) e nitrato de potássio (NP), aplicados no solo e via água de irrigação, com diferentes períodos de aplicação, até 42 dias após a germinação. Dados médios de quatro repetições. Petrolina, PE, 1996'.

\begin{tabular}{lccccccc}
\hline Tratamento & PR & PM & TSS & \multicolumn{4}{c}{ Tipo (\%) } \\
\cline { 6 - 8 } & $(\mathrm{t} / \mathrm{ha})$ & $(\mathrm{kg})$ & $\left({ }^{\circ} \mathrm{Brix}\right)$ & 6 & 8 & 10 & Outros \\
\hline Testemunha (sem N) & $25,06 \mathrm{bc}$ & $1,64 \mathrm{~b}$ & $12,2 \mathrm{a}$ & 43,2 & 40,0 & 15,0 & 1,8 \\
Uréia (solo) & $28,64 \mathrm{abc}$ & $1,63 \mathrm{~b}$ & $12,8 \mathrm{a}$ & 44,4 & 40,6 & 12,8 & 2,2 \\
Sulfato de amônio (solo) & $24,65 \mathrm{c}$ & $1,63 \mathrm{~b}$ & $12,7 \mathrm{a}$ & 40,5 & 35,2 & 14,8 & 0,5 \\
UR(42 dias):água & $31,14 \mathrm{a}$ & $1,84 \mathrm{a}$ & $12,5 \mathrm{a}$ & 34,3 & 44,0 & 20,9 & 0,8 \\
SA(42 dias):água & $26,87 \mathrm{abc}$ & $1,81 \mathrm{ab}$ & $12,2 \mathrm{a}$ & 48,0 & 32,8 & 17,9 & 1,3 \\
UR(15)+NP(16-42 dias):água & $26,59 \mathrm{bc}$ & $1,77 \mathrm{ab}$ & $12,9 \mathrm{a}$ & 51,6 & 37,6 & 10,8 & - \\
UR(15)+SA(16-42 dias):água & $30,48 \mathrm{ab}$ & $1,67 \mathrm{ab}$ & $12,6 \mathrm{a}$ & 48,9 & 38,0 & 11,5 & 1,6 \\
UR(30)+NP(31-42 dias):água & $28,34 \mathrm{abc}$ & $1,69 \mathrm{ab}$ & $13,1 \mathrm{a}$ & 42,3 & 40,7 & 16,6 & 0,4 \\
UR(15)+SA(16-30)+NP(31-42 dias):água & $27,73 \mathrm{abc}$ & $1,71 \mathrm{ab}$ & $12,1 \mathrm{a}$ & 45,9 & 36,8 & 14,3 & 3,0 \\
\hline CV (\%) & 11,90 & 6,70 & 3,4 & & & & \\
\hline
\end{tabular}

${ }^{1}$ Médias seguidas pela mesma letra na coluna não diferem entre si pelo teste de Duncan a $5 \%$ de probabilidade. 
comercializáveis, de 9 a 12, são comercializáveis, e acima de $12^{\circ}$ Brix são melões extras. Neste contexto, os teores de sólidos solúveis totais obtidos atendem tanto ao mercado externo como interno.

A produtividade de 25,06 t/ha (Tabela 1) de frutos comerciais, obtida com a testemunha (sem N), foi 2,3 vezes superior à produtividade de $10,83 \mathrm{t} / \mathrm{ha}$ obtida por Pinto et al. (1993), com a aplicação de N na forma convencional, na dose de $90 \mathrm{~kg} / \mathrm{ha}$, sem a incorporação de massa verde. Provavelmente, a crotolária incorporada ao solo, antes da instalação do experimento, elevou o teor de matéria orgânica do solo, influenciando positivamente todos os tratamentos.

A elevada dinâmica das formas de $\mathrm{N}$ no solo em boas condições de umidade provavelmente explica a eficiência semelhante entre as fontes de $\mathrm{N}$ e suas combinações utilizadas neste experimento.

Outro aspecto a ser levado em consideração é que em fertirrigação, os fertilizantes devem ter uma solubilidade elevada. Segundo Vitti et al. (1995), a solubilidade, à temperatura de $25^{\circ} \mathrm{C}$, da uréia, é de $1.200 \mathrm{~g} / \mathrm{L}$, a do sulfato de amônio é de $750 \mathrm{~g} / \mathrm{L}$, e a do nitrato de potássio é de $370 \mathrm{~g} / \mathrm{L}$. Provavelmente, essa menor solubilidade do nitrato de potássio em relação às outras fontes foi responsável pelo fato de a combinação das duas formas de $\mathrm{N}$ (nítrica e amoniacal) não ter sido mais eficiente do que a forma única de amônio, como relata a literatura. A uréia, sendo a mais solúvel, demonstrou, quando utilizada como a única fonte de $\mathrm{N}$ utilizada, uma tendência de ser mais eficiente do que o sulfato de amônio e outras combinações de fertilizantes nitrogenados utilizadas na fertirrigação.

Esses resultados indicam que a uréia aplicada de forma isolada ou combinada com outros fertilizantes nitrogenados, via água de irrigação, não afetaram a produtividade, o peso médio e a qualidade dos frutos do melão.

\section{CONCLUSÕES}

1. Não há diferenças significativas entre os fertilizantes nitrogenados e suas combinações aplicadas via água de irrigação.

2. A uréia aplicada via água de irrigação é mais eficiente do que a uréia e o sulfato de amônio aplicados no solo, em relação ao peso médio do fruto.

\section{REFERÊNCIAS}

BRASIL. Ministério da Indústria, do Comércio e do Turismo. Secretaria do Comércio Exterior. Banco de dados Alice. Brasília: Departamento do Comércio Exterior, 1996.

CHOUDHURY, E.N.; CHOUDHURY, M.M.; NEGRÃO DIAS, F.A. Crotalárias para controle de nematóides em fruteiras irrigadas e melhoria das características físico-químicas dos solos. Petrolina: Embrapa-CPATSA, 1991.3p. (Embrapa-CPATSA. Pesquisa em Andamento, 64).

CHOUDHURY, E.N.; MILLAR, A.A. Características físico-hídricas de três Latossolos irrigados do Projeto Bebedouro. In: EMBRAPA. Centro de Pesquisa Agropecuária do Trópico Semi-Árido (Petrolina, $\mathrm{PE})$. Pesquisa em irrigação no trópico semi-árido: solo, água, planta. Petrolina, 1981. p.1-24. (Embrapa-CPATSA. Boletim de Pesquisa, 4).

ELAMIN, O.M.; WILCOX, G.E. Nitrogen form ratio influence on muskmelon growth, composition, and magnese toxicity. Journal of the American Society for Horticultural Science, v.11, n.3, p.320-322, 1986.

FARIA, C.M.B. de; PEREIRA, J.R.; POSSÍDIO, E.L. Adubação orgânica e mineral na cultura do melão em um vertissolo do Submédio São Francisco. Pesquisa Agropecuária Brasileira, Brasília, v.29, n.2, p.191-197, 1994.

GORGATTI NETO, A.; GAYET J.P.; BEINROTN, E.W.; MATALLO, M.; GARCIA, E.E.C.; GARCIA, A.E.; ARDITO, G.F.G.; BORDIN, M.R. Melão para exportação: procedimento de colheita e pós-colheita. Brasília: Embrapa-SPI/Frupex, 1994. 37p. (Frupex, Publicações Técnicas, 6).

HANADA, K. Studies of nitrogen nutrition for muskmelon. I. The influence of the form and the level of nitrogen supplied upon the growth of melon. Science Bulletin of the Faculty of Agriculture, v.34, n.3/4, p.67-79, 1980.

PEREIRA, J.M. de A.; SOUZA, R.A. de. Mapeamento detalhado da área de Bebedouro -Petrolina-PE. Recife: SUDENE, 1967. 57p.

PINTO, J.M.; SOARES, J.M.; CHOUDHURY, E.N.; PEREIRA, J.R. Adubação via água de irrigação na cultura do melão. Pesquisa Agropecuária Brasileira, Brasília, v.28, n.11, p.1263-1268, 1993. 
PINTO, J.M.; SOARES, J.M.; COSTA, N.D.; FARIA, C.M.B. de; BRITO, L.T. de L.; SILVA, D.J. Doses e períodos de aplicação de nitrogênio via água de irrigação na cultura do tomate. Horticultura Brasileira, Brasília, v.15, n.1, p.15-18, maio 1997.

PINTO, J.M.; SOARES, J.M.; PEREIRA, J.R; CHOUDHURY, E.N.; CHOUDHURY, M.M. Efeitos de períodos e freqüências da fertirrigação nitrogenada na produção de melão. Pesquisa Agropecuária Brasileira, Brasília, v.29, n.9, p.345-350, 1994.

PINTO, J.M.; SOARES, J.M.; PEREIRA, J.R; COSTA, N.D.; BRITO, L.T. de L.; FARIA, C.M.B. de; MACIEL, J.L. Sistema de Cultivo de melão com aplicação de fertilizantes via água de irrigação. Petrolina: Embrapa-CPATSA/Petrobrás, 1996. 24p. (Embrapa-CPATSA. Circular técnica, 36).

RAIJ, B. van; CANTARELLA, H.; QUAGGIO, J.A.; FURLANI, A.M.C. Recomendações de adubação e calagem para o Estado de São Paulo. 2.ed. Campinas: Instituto Agronômico \& Fundação IAC, 1996. 285p. (Boletim técnico, 100).

SUAREZ, C.D.; RAMIREZ, C. Incidencia de la época de siembra en el comportamiento de cuatro variedades de melon (Cucumis melo L.) em Azua, República Dominicana. Investigación, v.9, n.1, p.59-64, 1985.

VITTI, G.C.; HOLANDA, J.S.; LUZ, P.H.C.; HERNANDEZ, F.B.T.; BOARETTO, A.E.; PENTEADO, S.R. Fertirrigação: condições e manejo. In: REUNIÃO BRASILEIRA DE FERTILIDADE DO SOLO E NUTRIÇÃO DE PLANTAS, 21., 1994, Petrolina, PE. Anais... Petrolina: EmbrapaCPATSA/SBCS, 1995. p.195-271.

YAMAGUCHI, M.; HUGHES, D.L.; YABUMOTO, K.; JENNINGS, W.G. Quality of cantaloupe muskmelon variability and attributes. Science Horticulture, Amsterdam, v.1, n.1, p.59-70, 1977. 